\title{
Antibacterial Efficacy of Raw and Processed Honey
}

\author{
D. P. Mohapatra, ${ }^{1}$ V. Thakur, ${ }^{2}$ and S. K. Brar ${ }^{1}$ \\ ${ }^{1}$ INRS-ETE, Université du Québec, Québec, QC, Canada G1K 9A9 \\ ${ }^{2}$ Biochemical and Bioprocess Engineering Group, Amity Institute of Biotechnology, Amity University, Noida, \\ Uttar Pradesh 201303, India \\ Correspondence should be addressed to S. K. Brar, satinder.brar@ete.inrs.ca
}

Received 15 September 2010; Revised 11 November 2010; Accepted 18 December 2010

Academic Editor: Kari E. Dunfield

Copyright (C) 2011 D. P. Mohapatra et al. This is an open access article distributed under the Creative Commons Attribution License, which permits unrestricted use, distribution, and reproduction in any medium, provided the original work is properly cited.

In vitro antibacterial activity of methanol, ethanol, and ethyl acetate extracts of raw and processed honey was tested against Grampositive bacteria (Staphylococcus aureus, Bacillus subtilis, Bacillus cereus, Enterococcus faecalis, and Micrococcus luteus) and Gramnegative bacteria (Escherichia coli, Pseudomonas aeruginosa, and Salmonella typhi). Both types of honey showed antibacterial activity against tested organisms with the zone of inhibition (ZOI) ranging from 6.94 to $37.94 \mathrm{~mm}$, while E. coli, S. typhi, and $P$. aeruginosa showed that sensibility towards all the extracts with ZOI ranges between 13.09 to $37.94 \mathrm{~mm}$. The methanol extract showed more potent activity than other organic extracts. Gram-negative bacteria were found to be more susceptible as compared to Gram-positive bacteria except E. faecalis. The broth microdilution assay gave minimum inhibitory concentrations (MIC) value of $625 \mu \mathrm{g} / \mathrm{mL}$, while the minimum bactericidal concentration (MBC) ranges between $625 \mu \mathrm{g} / \mathrm{mL} 2500 \mu \mathrm{g} / \mathrm{mL}$. The study showed that honey has antibacterial activity (bacteriostatic and bactericidal effect), similar to antibiotics, against test organisms and provides alternative therapy against certain bacteria.

\section{Introduction}

Natural products and their derivatives (including antibiotics) represent more than $50 \%$ of all drugs in clinical use in the world. According to World Health Organization estimates, about 80 percent of people living in developing countries rely on harvested wild plants for some part of their primary health care [1]. There are several reports on the antimicrobial activity of different herbal extracts in different regions of the world [2, 3]. Due to the side effects and the resistance that pathogenic microorganisms have developed against antibiotics, recently much attention has been paid to extracts and biologically active compounds isolated from natural species used in herbal medicine.

The antibacterial activity of honey was first recognized in 1892, by Dustmann [4]. Honey has been used as a medicine in many cultures for a long time. However, it has a limited use in medicine due to lack of scientific support [5]. It has been rediscovered by the medical profession and it is gaining acceptance as an antibacterial treatment of topical infections resulting from burns and wounds [6]. It is well established that honey inhibits a broad spectrum of bacterial species. More recently, honey has been reported to have an inhibitory effect to around 60 species of bacteria including aerobes and anaerobes, Gram positives, and Gram negatives [7]. There are many reports of bactericidal as well as bacteriostatic activity of honey and the antibacterial properties of honey may be particularly useful against bacteria, which have developed resistance to many antibiotics [8].

Honey has been reported to be effective in the healing of infected postoperative wounds [9]. The in vitro antimicrobial activity of honey was reported by Radwan et al. [10] who observed that honey stopped the growth of Salmonella and Escherichia coli. Honey has a potent antibacterial activity and is very effective in clearing infection in wounds and protecting them from becoming infected [11]. Honey has been useful in the treatment of infected surgical wounds, burn wounds, and decubitus ulcers (bedsores). It maintains a moist wound environment that promotes healing, and its high viscosity helps to provide a protective barrier to prevent infection. Low concentrations of this known antiseptic are effective against infectious bacteria and can play a role in 
the wound healing mechanism [12] and in stimulation and proliferation of peripheral blood lymphocytic and phagocytic activity. In addition, the mild acidity and lowlevel hydrogen peroxide release assists both tissue repair and contributes to the antibacterial activity [13].

In general, all types of honey have high sugar content but a low water content and acidity, which prevent microbial growth. Most types of honey generate hydrogen peroxide when diluted because of the activation of the enzyme glucose oxidase, which oxidizes glucose to gluconic acid and hydrogen peroxide [14]. Hydrogen peroxide is the major contributor to the antimicrobial activity of honey, and the different concentrations of this compound in different honeys result in their varying antimicrobial effects [15]. Besides its antimicrobial properties, honey can clear infection in a number of ways, including boosting the immune system, having anti-inflammatory and antioxidant activities, and via stimulation of cell growth [16].

Therefore, the purpose of the present study was to evaluate in vitro antibacterial activity (bacteriostatic and bactericidal effect) of honey against eight different bacterial cultures such as Staphylococcus aureus (MTCC-737), Bacillus subtilis (MTCC-736), Bacillus cereus (MTCC-430), Pseudomonas aeruginosa (MTCC-731), Escherichia coli (MTCC1687), Salmonella typhi (MTCC-531), Enterococcus faecalis (MTCC-439), and Micrococcus-luteus (MTCC-2470).

\section{Materials and Methods}

2.1. Media and Chemicals. The different media used such as Mueller Hinton Agar (MHA), Soybean Casein Digest Agar (TSA), Nutrient Agar (NA), and Soyabean Casein Digest Medium (Tryptone Soya Broth) (SCDB) were purchased from HIMEDIA, India. HPLC grade methanol $(\mathrm{MeOH})$, ethyl acetate, ethanol, and dimethyl sulphoxide (DMSO), used for cleaning and extraction purposes, were purchased from Fisher Scientific (Powai, Mumbai, India). HPLC grade water was prepared in the laboratory using a Milli-Q/MilliRO Millipore system (Milford, MA, USA).

2.2. Antibiotics. The antibiotics used included CIPROFLOXACIN: Ciprofloxacin Hydrochloride Tablets IP $(500 \mathrm{mg})$ Ciplox-500, B.No. D80502, Mfg. date: February 2008, Exp. date: January 2011, Mfd. by Cipla limited; TETRACYCLINE: Tetracycline Hydrochloride Capsules IP (500 mg) Hostacycline 500. B.NO. 217292, Mfg. date-October 2007, Exp. Date: March 2009, Mfd. by, Aventis Pharma limited.

2.3. Microbial Cultures and Collection of Honey Samples by Bacterial Strains. A total of nine microbial cultures belonging to eight bacteria and one yeast species were used in this study. The list of microorganisms used with their pathogenicity data is presented in Table 1. Microorganisms were provided by the ShriRam Institute for Industrial Research, Delhi, India. Two honey samples were taken considered as raw and processed honey, respectively. The raw honey (batch no. S-07) provided by ShriRam Institute for Industrial
Research, Delhi, India and the processed honey were taken commercially.

2.4. Preparation of Crude Extract. The active components of honey were extracted with methanol, ethanol, and ethyl acetate on the basis of polarity. The raw and processed honey $(10 \mathrm{~g}$ each) was taken in two test tubes, and $25 \mathrm{~mL}$ of methanol was added. Later, the solution was mixed well by vortexing and centrifuged at $3000 \mathrm{rpm}$ for $10 \mathrm{~min}$ at $25^{\circ} \mathrm{C}$. The supernatant was collected from each test tube and transferred to stoppered test tube by filtrations. The resulting supernatant was evaporated to dryness with a gentle stream of nitrogen and reconstituted with $10 \mathrm{~mL}$ dimethyl sulphoxide and mixed well by vortexing. Same procedure was followed for raw and processed honey with ethanol and ethyl acetate.

2.5. Subculturing of Test Organisms and Preparations of the Bacterial Inoculum. The test organisms were taken from Microbial Type Culture Collections (MTCC) (Institute of Microbial Technology, Chandigarh) which is traceable to American Type Culture Collections (ATCC). All reference bacterial and fungal cultures were subcultured on Nutrient Agar. The bacterial slants were incubated overnight at $37^{\circ} \mathrm{C}$, and the fungal slant was incubated for $48 \mathrm{~h}$ at $37^{\circ} \mathrm{C}$.

Mcfarland density of bacterial and fungal culture was adjusted in normal saline $(85 \%, \mathrm{v} / \mathrm{v})$ using densitometer to achieve the final concentration of $1 \times 10^{8} \mathrm{cfu} / \mathrm{mL}$ of each test organism individually. This had been used as adjusted inoculum for all the further studies.

2.6. Antimicrobial Assay. In vitro antibacterial activity of honey extracts of methanol, ethanol, and ethyl acetate was evaluated using the agar well-diffusion assay [17]. Adjusted culture $(100 \mu \mathrm{L})$ was mixed with $100 \mathrm{~mL}$ of Muller Hinton Agar (MHA) and poured $25 \mathrm{~mL}$ each into sterile petri dishes $(90 \mathrm{~mm})$ this was allowed to solidify, and then individual plates were marked for the organisms inoculated. After solidification, plates were punched to make the well of $6 \mathrm{~mm}$ diameter with the help of sterile cork borer. Methanol, ethanol and ethyl acetate extracts $(100 \mu \mathrm{L}$ each) were poured into the well in assay plates [18]. Plates were incubated overnight at $37^{\circ} \mathrm{C}$, and all the plates were observed for the zone of inhibition; diameter of these zones were measured in millimeters by using Vernier caliper. The positive (standard antibiotics ciprofloxacin and tetracycline of $5 \mu \mathrm{g} / \mathrm{mL}$ ) and negative (DMSO, methanol, ethanol, and ethyl acetate) controls were examined by the same procedure. The solvent control revealed no activity.

2.7. Minimum Inhibitory Concentration (MIC). The broth dilution technique was used to ascertain the MIC of the honey samples. The test was carried out as described by Heuvelink et al. [19]. The methanol extracts of E. coli, P. aeruginosa, S. typhi, B. subtilis, B. cereus, and M. luteus which showed significant antibacterial activity were selected for determination of MIC. A stock solution $1000 \mu \mathrm{g} / \mathrm{mL}$ was prepared by dissolving $5 \mathrm{mg}$ of methanol extract added in $5 \mathrm{~mL}$ 
TABLE 1: List of microorganisms used with their pathogenicity and Gram reaction.

\begin{tabular}{lccccc}
\hline Name of organism & $\begin{array}{c}\text { MTCC } \\
\text { no. }\end{array}$ & $\begin{array}{c}\text { ATCC } \\
\text { no. }\end{array}$ & $\begin{array}{c}\text { NCTC } \\
\text { no. }\end{array}$ & Pathogenicity & Gram reaction \\
\hline Staphylococcus aureus & 737 & 6538 & 7447 & Nonpathogenic & Gram-positive \\
Bacillus subtilis & 736 & 6633 & - & Pathogenic & Gram positive \\
Bacillus cereus & 430 & 11778 & 10320 & Nonpathogenic & Gram positive \\
Pseudomonas aeruginosa & 741 & 25668 & 10662 & Nonpathogenic & Gram negative \\
Escherichia coli & 1687 & 8739 & - & Nonpathogenic & Gram negative \\
Salmonella typhi & 531 & 6539 & - & Nonpathogenic & Gram negative \\
Micrococcus luteus & 2470 & - & - & Nonpathogenic & Gram positive \\
Enterococcus faecalis & 439 & - & - & Pathogenic & Gram positive \\
\hline
\end{tabular}

TABLE 2: Antimicrobial susceptibility of raw honey.

\begin{tabular}{lccccc}
\hline \multirow{2}{*}{ Test organisms } & \multicolumn{2}{c}{ Extracts } & \multicolumn{2}{c}{ Antibacterial activity (zone of inhibition in mm) } \\
& Methanol & Ethanol & Ethyl acetate & Ciprofloxacin & Tetracycline \\
\hline & & & & & \\
S. aureus MTCC-737 & $8.58 \pm 3$ & $8.9 \pm 5$ & $9.15 \pm 1$ & $14.75 \pm 0.9$ & $26.44 \pm 5.2$ \\
B. cereus MTCC-430 & $11.11 \pm 6$ & $12.83 \pm 9$ & $11.46 \pm 7$ & $16.67 \pm 2.2$ & $17.01 \pm 0.81$ \\
B. subtilis MTCC-736 & $8.55 \pm 2$ & nd & $11.19 \pm 9$ & $19.01 \pm 2$ & $21.01 \pm 3.2$ \\
M. luteus MTCC-2470 & $11.21 \pm 10$ & $9.97 \pm 2$ & $10.77 \pm 4$ & $23.85 \pm 0.4$ & $19.11 \pm 1.6$ \\
S. typhi MTCC-531 & $34.39 \pm 4$ & $31.85 \pm 3$ & nd & $14.75 \pm 1.7$ & $26.96 \pm 4.3$ \\
E. coli MTCC-1687 & $26.49 \pm 6$ & $17.51 \pm 5$ & $17.15 \pm 4$ & $16.67 \pm 3.5$ & $16.03 \pm 0.49$ \\
P. aeruginosa MTCC-741 & $35.95 \pm 11$ & $32.35 \pm 14$ & $13.09 \pm 9$ & $19.01 \pm 0.83$ & $11.68 \pm 0.03$ \\
E. faecalis MTCC-439 & nd & nd & nd & nd & nd \\
\hline
\end{tabular}

\pm refers to standard error, nd: not detected.

of DMSO. This was serially twofold diluted by using SCDB (Soya Bean Casein Digest Broth) to obtain various ranges of concentrations between $2500 \mu \mathrm{g} / \mathrm{mL}$ and $312.5 \mu \mathrm{g} / \mathrm{mL}$. A volume of $100 \mu \mathrm{g} / \mathrm{mL}$ of the bacterial suspension adjusted previously at concentration $10^{8} \mathrm{CFU} / \mathrm{mL}$ was added, and an additional tube containing broth only was used as a negative control. All the test tubes and control were incubated at $37^{\circ} \mathrm{C}$ for $18-24 \mathrm{~h}$. After the period of incubation, the tube containing the least concentration of extracts showing no visible growth was considered as MIC [20].

2.8. Minimum Bactericidal Concentration (MBC). From the tubes showing no visible sign of growth/turbidity in MIC determination, test microorganisms were inoculated onto sterile nutrient agar plates by streak plate method. The plates were then incubated at $37^{\circ} \mathrm{C}$ for $24 \mathrm{~h}$. The least concentration that did not show growth of test organisms was considered as the MBC.

\section{Results and Discussion}

3.1. Antibacterial Susceptibility Testing. Tables 2 and 3 show the results of in vitro susceptibility of the extracts of raw and processed honey having varying degree of antibacterial activity against Gram-positive as well as Gram-negative bacteria using methanol, ethanol, and ethyl acetate. These might be due to the osmotic effect, the effect of $\mathrm{pH}$, and the sensitivity of these organisms to hydrogen peroxide which are unsuitable for bacterial growth, represented as an "inhibition" factor in honey [21]. Major variations seen in overall antibacterial activity were due to changes in the level of hydrogen peroxide achieved and in some cases to the level of nonperoxide factors. The content of nonperoxide factors was obviously related to the floral source and sometimes accounted for the major part of the antibacterial activity in honey [22]. However, hydrogen peroxide concentration produced in honey was typically around $1 \mathrm{mmol} / \mathrm{L}$ [15], about 1000 times less than 3\% solution commonly used as an antiseptic. The harmful effects of hydrogen peroxide were further reduced as honey sequesters and inactivates free iron which catalyzes the formation of oxygen free radicals produced by hydrogen peroxide [23], and its antioxidant components help to mop up oxygen free radicals [24].

Both raw and processed honey showed the inhibitory effects which were inherent mostly in all selected test organisms except E. faecalis. Further study by Basualdo et al. [25] also revealed the same results. S. typhi, P.aeruginosa, and $E$. coli showed significant antibacterial activity with the ZOI range between $37.94 \mathrm{~mm}$ and $13.94 \mathrm{~mm}$. The significant activity may be due to the property of honey which has higher level of hydrogen peroxide along with osmolarity. Also, methanol extracts showed that maximum ZOI between 
TABLE 3: Antimicrobial susceptibility of processed honey.

\begin{tabular}{|c|c|c|c|c|c|}
\hline \multirow{3}{*}{ Test organisms } & \multicolumn{5}{|c|}{ Antibacterial activity (zone of inhibition in $\mathrm{mm}$ ) } \\
\hline & \multicolumn{2}{|c|}{ Extracts } & & \multicolumn{2}{|c|}{ Positive control } \\
\hline & Methanol & Ethanol & Ethyl acetate & Ciprofloxacin & Tetracycline \\
\hline S. aureus MTCC-737 & $11.54 \pm 2.1$ & nd & $9.15 \pm 3.8$ & $14.75 \pm 1.0$ & $26.44 \pm 1.7$ \\
\hline B. cereus MTCC- 430 & $23.70 \pm 1$ & $6.94 \pm 1.4$ & nd & $16.67 \pm 1.8$ & $17.01 \pm 4.2$ \\
\hline B. subtilis MTCC-736 & nd & $7.83 \pm 5.5$ & $7.25 \pm 2.3$ & $19.01 \pm 4.3$ & $21.01 \pm 6.1$ \\
\hline M. luteus MTCC- 2470 & $18.52 \pm 2.1$ & nd & nd & $23.85 \pm 0.9$ & nd \\
\hline S. typhi MTCC-531 & $37.94 \pm 11.7$ & $35.92 \pm 13.2$ & $36.58 \pm 7.9$ & $14.75 \pm 3.1$ & $26.96 \pm 0.9$ \\
\hline E. coli MTCC-1687 & $28.49 \pm 5.1$ & $16.14 \pm 7.3$ & $17.75 \pm 11.2$ & $16.67 \pm 0.9$ & $16.03 \pm 1.1$ \\
\hline P. aeruginosa MTCC-741 & $33.40 \pm 5$ & $23.43 \pm 14.1$ & $24.60 \pm 13.5$ & $19.01 \pm 1.7$ & $11.03 \pm 0.51$ \\
\hline E. faecalis MTCC-439 & $8.13 \pm 1.7$ & nd & nd & nd & nd \\
\hline
\end{tabular}

\pm refers-standard error, nd: not detected.

TABLE 4: Minimum inhibitory concentration (MIC) and minimum bactericidal concentration (MBC) of raw honey methanol extract.

\begin{tabular}{lcccccc}
\hline & \multicolumn{4}{c}{ Test organisms } \\
& B. subtilis & E. coli & P. aeruginosa & S. typhi & B. cereus & M. luteus \\
\hline $\operatorname{MIC}(\mu \mathrm{g} / \mathrm{mL})$ & $625 \pm 17$ & $625 \pm 23$ & $625 \pm 37$ & $625 \pm 19$ & $625 \pm 8$ & $625 \pm 11$ \\
$\operatorname{MBC}(\mu \mathrm{g} / \mathrm{mL})$ & $625 \pm 23$ & $2500 \pm 11$ & $1250 \pm 14$ & $1250 \pm 27$ & $625 \pm 23$ & $1250 \pm 32$ \\
\hline
\end{tabular}

\pm refers-standard error.

the ranges 37.94 and $8.13 \mathrm{~mm}$ refer to all test organisms ((Staphylococcus aureus (MTCC-737), Bacillus subtilis (MTCC-736), Bacillus cereus (MTCC-430), Pseudomonas aeruginosa (MTCC-731), Escherichia coli (MTCC-1687), Salmonella typhi (MTCC-531), Enterococcus faecalis (MTCC439), and Micrococcus-luteus (MTCC-2470)). Any zone having diameter less than $7 \mathrm{~mm}$ showed that the microorganisms were resistant to the honey sample. However, zone diameter greater than $11 \mathrm{~mm}$ suggested that the microorganism was sensitive to the honey sample [26]. The Gram-negative bacteria showed increased inhibition except E. faecalis as compared to Gram-positive bacteria. AI-Namma, [27] also observed that honey has a greater inhibitory effect on Gramnegative bacteria. S. typhi, P.aeruginosa, and E. coli are more susceptible than other test organisms, and honey may have potential as therapeutic honeys.

The inhibitory activity against test microorganisms is of interest because these organisms cause infection. The methanol extracts showed highest activity on test organism as compared to ethanol and ethyl acetate. This may be due to better solubility and polarity of the active components in methanol compared to ethanol and ethyl acetate. If such components are present in these raw and processed honey extracts, they could be used for the management of ailments caused by these pathogenic bacteria and give impressive results which could only be determined in vivo.

Results in Table 3 also showed that test organisms exhibited varying degrees of multidrug resistance of standard antibiotics used in this study. The test organisms used in this study were resistant to ciprofloxacin, and tetracycline $5 \mu \mathrm{g} / \mathrm{mL}$ with the methanol, ethanol, and ethyl acetate extracts showed positive results with the ZOI ranges between $14.75-27.01 \mathrm{~mm}$. The results showed that all positive controls had ZOI higher than $11 \mathrm{~mm}$ causing sensitivity to microorganisms. When comparing ZOI values of positive control with raw honey extracts (Table 2), it was observed that most of the extracts showed ZOI value more than $11 \mathrm{~mm}$. However, when compared to antibacterial activity of the methanol, ethanol, and ethyl acetate extracts, it was observed that the inhibitory activity of the extracts of E. coli, S. typhi, and P. aeruginosa (Gram negative) was greater than those of standard antibiotics, ciprofloxacin and tetracycline. Even tetracycline did not show any inhibitory activity against $P$. aeruginosa which is shown by the extracts; this may be explained by the fact that tetracycline showed lower ZOI (11.68 mm (raw honey) and $11.03 \mathrm{~mm}$ (processed honey) with $P$. aeruginosa. The results were in agreement with Subrahmanyam et al. [28] who showed that strains of $P$. aeruginosa were resistant to routinely used and higher antibiotics were sensitive to the antibacterial action of honey. Methanol extracts showed greater activity than standard antibiotics. Its potency was comparable to that of standard antibiotics. These results also suggested that the honey samples used contain biocomponents whose antibacterial activities are highly comparable with those of the two regular antibiotics (tetracycline and ciprofloxacin).

3.2. Effects of Minimum Inhibitory Concentrations (MIC) and Minimum Bactericidal Concentration (MBC). Minimum inhibitory concentrations (MIC) for the active extract was determined by macrodilution method. Results in Tables 4 and 5 showed that the MIC values for five test organisms, such as B. subtilis, M. luteus, E. coli, P. aeruginosa, and S. typhi, were $625 \mu \mathrm{g} / \mathrm{mL}$. The MIC value indicates the inhibitory concentration at which honey showed no visible growth of any test organisms.

The MBC value of both honey samples was in the range $625-2500 \mu \mathrm{g} / \mathrm{mL}$. Table 4 showed that MBC values for 
TABLE 5: Minimum inhibitory concentration (MIC) and minimum bactericidal concentration (MBC) of processed honey methanol extract.

\begin{tabular}{lcccccc}
\hline & \multicolumn{4}{c}{ Test organisms } \\
& B. subtilis & E. coli & P. aeruginosa & S. typhi & B. cereus & M. luteus \\
\hline MIC $(\mu \mathrm{g} / \mathrm{mL})$ & $625 \pm 38$ & $625 \pm 9$ & $625 \pm 7$ & $625 \pm 11$ & $625 \pm 17$ \\
$\operatorname{MBC}(\mu \mathrm{g} / \mathrm{mL})$ & $2500 \pm 12$ & $2500 \pm 16$ & $1250 \pm 21$ & $2500 \pm 18$ & $1250 \pm 6$ \\
\hline
\end{tabular}

\pm refers-standard error.

S. typhi, P. aeruginosa, E. coli, M. luteus, B. cereus and B. subtilis were $1250 \mu \mathrm{g} / \mathrm{mL}, 1250 \mu \mathrm{g} / \mathrm{mL}, 2500 \mu \mathrm{g} / \mathrm{mL}, 1250 \mu \mathrm{g} / \mathrm{mL}$, $625 \mu \mathrm{g} / \mathrm{mL}$, and $625 \mu \mathrm{g} / \mathrm{mL}$, respectively, in the case of raw honey. Table 5 showed that the MBCs values of processed honey for S. typhi, P. aeruginosa, E. coli, M.luteus, B. cereus, and B. subtilis were $2500 \mu \mathrm{g} / \mathrm{mL}, 1250 \mu \mathrm{g} / \mathrm{mL}, 2500 \mu \mathrm{g} / \mathrm{mL}$, $1250 \mu \mathrm{g} / \mathrm{mL}, 1250 \mu \mathrm{g} / \mathrm{mL}$, and $2500 \mu \mathrm{g} / \mathrm{mL}$, respectively. When a ratio between $\mathrm{MBC}$ processed to $\mathrm{MBC}$ raw honey was considered, a higher ratio of 4 was observed for E. coli. Based on these studies, it was observed that methanol extract has a stronger and broad spectrum of antibacterial activities. Earlier studies have reported better and strong antibacterial activities with ethyl acetate extract, but in the present study methanol extract showed better and maximum inhibitory activity as compared to ethanol and ethyl acetate extracts, respectively. This may be due to different polarity of raw and processed honey and also because of better solubility of methanol as compared to ethanol and ethyl acetate.

Among all the extracts analyzed in this paper, the methanol extract was the most effective as an antibacterial agent. Concerning variation in antibacterial activity in almost all reports on the medical use of honey as an antibacterial agent, no consideration is given to the selection of type of honey for therapeutic use. Honey as natural antibiotic can be used to cure infections as a substitute to conventional drugs.

\section{Conclusion}

The present study concluded that honey has both bacteriostatic as well as bactericidal activity against many pathogens. Honey samples of methanol extracts resulted in a broad spectrum of antibacterial activity. The study showed that honey, a kin to antibiotics, possesses certain organisms sensitive to it and provides alternative therapy against certain bacteria. Therefore, there is need to characterize the active components of honey extracts and encourage to investigate possible benefits of the use of honey among therapies in the treatment of bacterial infections.

\section{Abbreviations}

ZOI: Zone of inhibition

MIC: Minimum inhibitory concentrations

MBC: Minimum bactericidal concentration

MHA: Mueller hinton agar

TSA: Soyabean casein digest agar

NA: Nutrient agar

SCDB: Soya bean casein digest broth

DMSO: Dimethyl sulphoxide.

\section{Acknowledgment}

The authors are sincerely thankful to the Natural Sciences and Engineering Research Council of Canada (Discovery Grants A4984, Canada Research Chair) and INRS-ETE for financial support.

\section{References}

[1] E. Elisabetsky, M. J. Balick, and S. A. Laird, Medicinal Resources of the Tropical Forest: Biodiversity and Its Importance to Human Health, Columbia University Press, New York, NY, USA, 1996.

[2] K. A. Hammer, C. F. Carson, and T. V. Riley, "Antimicrobial activity of essential oils and other plant extracts," Journal of Applied Microbiology, vol. 86, no. 6, pp. 985-990, 1999.

[3] M. Gulluce, M. Sokmen, D. Daferera et al., "In vitro antibacterial, antifungal, and antioxidant activities of the essential oil and methanol extracts of herbal parts and callus cultures of Satureja hortensis L," Journal of Agricultural and Food Chemistry, vol. 51, no. 14, pp. 3958-3965, 2003.

[4] J. H. Dustmann, "Antibacterial effect of honey," Apiacta, vol. 14, no. 1, pp. 7-11, 1989.

[5] A. T. Ali, M. N. Chowdhury, and M. S. al Humayyd, "Inhibitory effect of natural honey on Helicobacter pylori," Tropical Gastroenterology, vol. 12, no. 3, pp. 139-143, 1991.

[6] N. Abuharfeil, R. Al-Oran, and M. Abo-Shehada, "The effect of bee honey on the proliferative activity of human B- and T-lymphocytes and the activity of phagocytes," Food and Agricultural Immunology, vol. 11, no. 2, pp. 169-177, 1999.

[7] A. Hannan, M. Barkaat, S. Saleem, M. Usman, and W. A. Gilani, Manuka honey and its antimicrobial potential against multi drug resistant strains of Typhoidal salmonellae, Ph.D. thesis, Department of Microbiology, University of Health Science, Lahore, Pakistan, 2004.

[8] T. Patton, J. Barrett, J. Brennan, and N. Moran, "Use of a spectrophotometric bioassay for determination of microbial sensitivity to manuka honey," Journal of Microbiological Methods, vol. 64, no. 1, pp. 84-95, 2006.

[9] N. S. Al-Waili and K. Y. Saloom, "Effects of topical honey on post-operative wound infections due to gram positive and gram negative bacteria following caesarean sections and hysterectomies," European Journal of Medical Research, vol. 4, no. 3, pp. 126-130, 1999.

[10] S. S. Radwan, A. A. El-Essawy, and M. M. Sarhan, "Experimental evidence for the occurrence in honey of specific substances active against microorganisms," Zentralblatt fur Mikrobiologie, vol. 139, no. 4, pp. 249-255, 1984.

[11] L. Boukraa, H. Benbarek, and A. Moussa, "Synergistic action of starch and honey against Candida albicans in correlation with diastase number," Brazilian Journal of Microbiology, vol. 39, no. 1, pp. 40-43, 2008.

[12] P. C. Molan, "Potential of honey in the treatment of wounds and burns," American Journal of Clinical Dermatology, vol. 2, no. 1, pp. 13-19, 2001. 
[13] V. Mullai and T. Menon, "Bactericidal activity of different types of honey against clinical and environmental isolates of Pseudomonas aeruginosa," Journal of Alternative and Complementary Medicine, vol. 13, no. 4, pp. 439-441, 2007.

[14] A. I. Schepartz and M. H. Subers, "The glucose oxidase of honey I. Purification and some general properties of the enzyme," Biochimica et Biophysica Acta, vol. 85, no. 2, pp. 228237, 1964.

[15] P. C. Molan, "The antibacterial activity of honey: the nature of the antibacterial activity," Bee World, vol. 73, no. 1, pp. 5-28, 1992.

[16] A. A. Al-Jabri, "Honey, milk and antibiotics," African Journal of Biotechnology, vol. 4, no. 13, pp. 1580-1587, 2005.

[17] C. Perez, M. Pauli, and P. Bazerque, "An antibiotic assay by agar-well diffusion method," Acta Biologiae et Medecine Experimentaalis, vol. 15, pp. 113-115, 1990.

[18] P. Kaushik and A. Chauhan, "In vitro antibacterial activity of laboratory grown culture of Spirulina platensis," Indian Journal of Microbiology, vol. 48, no. 3, pp. 348-352, 2008.

[19] A. E. Heuvelink, F. L. A. M. Van Den Biggelaar, J. T. M. Zwartkruis-Nahuis et al., "Occurrence of verocytotoxinproducing Escherichia coli O157 on Dutch dairy farms," Journal of Clinical Microbiology, vol. 36, no. 12, pp. 3480-3487, 1998.

[20] N. De and E. Ifeoma, "Antibacterial effects of components of the bark extract of neem (Azadirachta indica A. Juss)," Technology and Development, vol. 8, pp. 23-28, 2002.

[21] T. Postmes, A. E. Van den Bogaard, and M. Hazen, "Honey for wounds, ulcers, and skin graft preservation," The Lancet, vol. 341, no. 8847, pp. 756-757, 1993.

[22] P. C. Molan and K. M. Russell, "Non-peroxide antibacterial activity in some New Zealand honeys," Journal of Apicultural Research, vol. 27, no. 1, pp. 62-67, 1988.

[23] C. M. Bunting, The production of hydrogen peroxide by honey and its relevance to wound healing, M.S. thesis, University of Waikato, 2001.

[24] S. Frankel, G. E. Robinson, and M. R. Berenbaum, "Antioxidant capacity and correlated characteristics of 14 unifloral honeys," Journal of Apicultural Research, vol. 37, no. 1, pp. 2731, 1998.

[25] C. Basualdo, V. Sgroy, M. S. Finola, and J. M. Marioli, "Comparison of the antibacterial activity of honey from different provenance against bacteria usually isolated from skin wounds," Veterinary Microbiology, vol. 124, no. 3-4, pp. 375-381, 2007.

[26] O. E. Agbagwa and N. Frank-Peterside, "Effect of raw commercial honeys from nigeria on selected pathogenic bacteria," African Journal of Microbiology Research, vol. 4, no. 16, pp. 1801-1803, 2010.

[27] R. T. AI-Namma, "Evalution of in vitro inhibitory effect of honey on some microbial isolate," Journal of Bacteriology Research, vol. 1, no. 6, pp. 64-67, 2009.

[28] M. Subrahmanyam, A. R. Hemmady, and S. G. Pawar, "Antibacterial activity of honey on bacteria isolated from wounds," Annals of Burne and Fires Disasters, vol. 14, no. 1, pp. 198-201, 2001. 

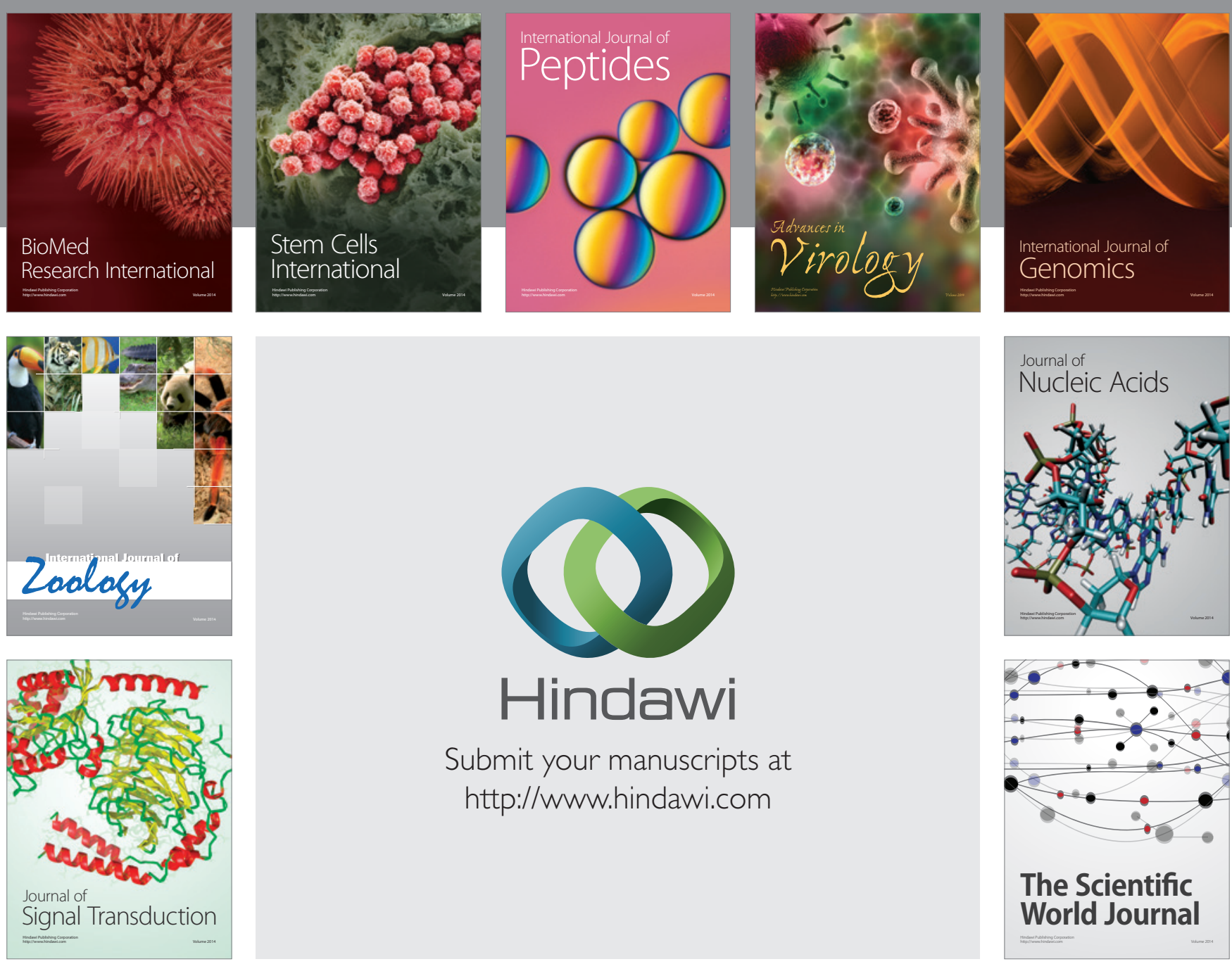

Submit your manuscripts at

http://www.hindawi.com
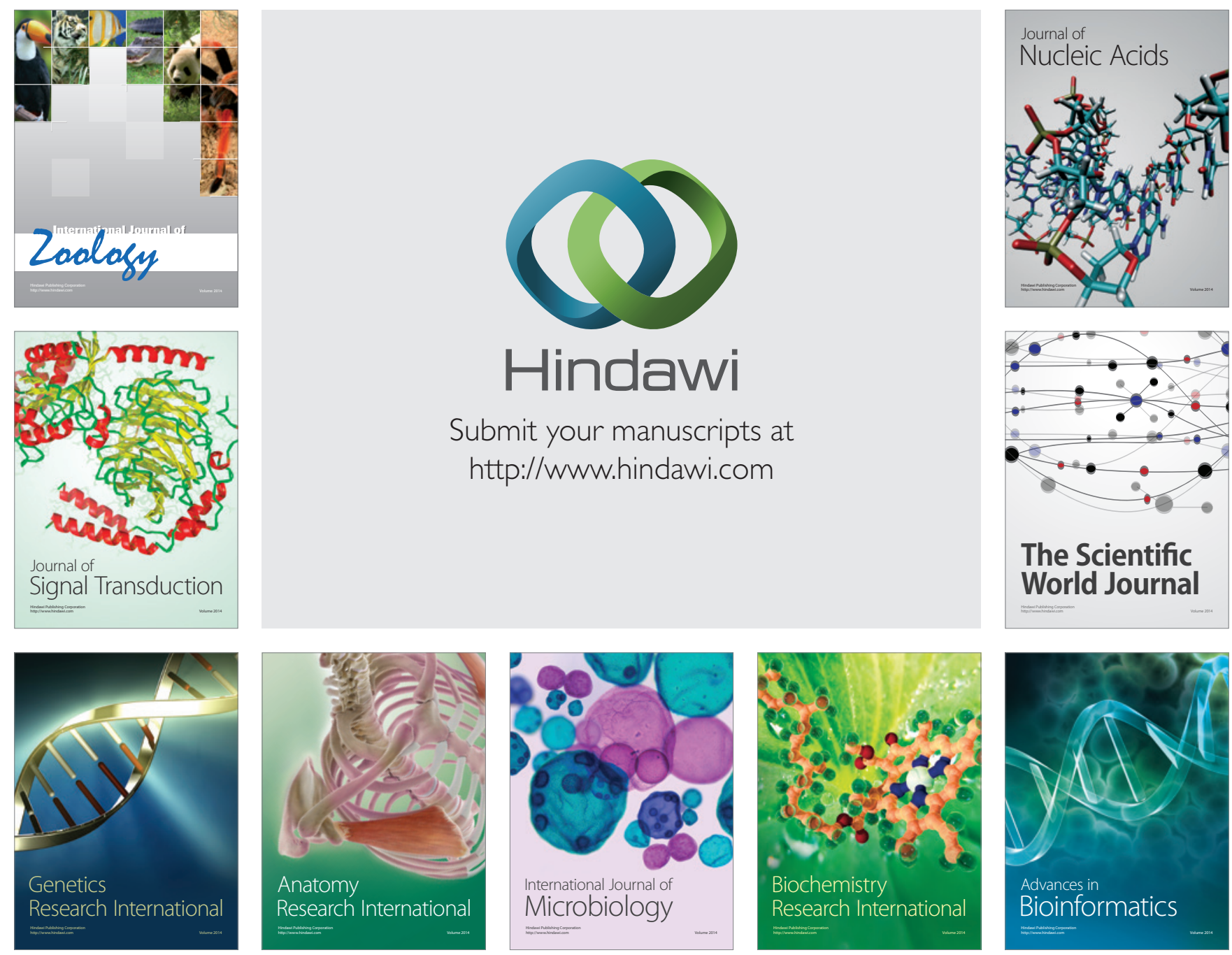

The Scientific World Journal
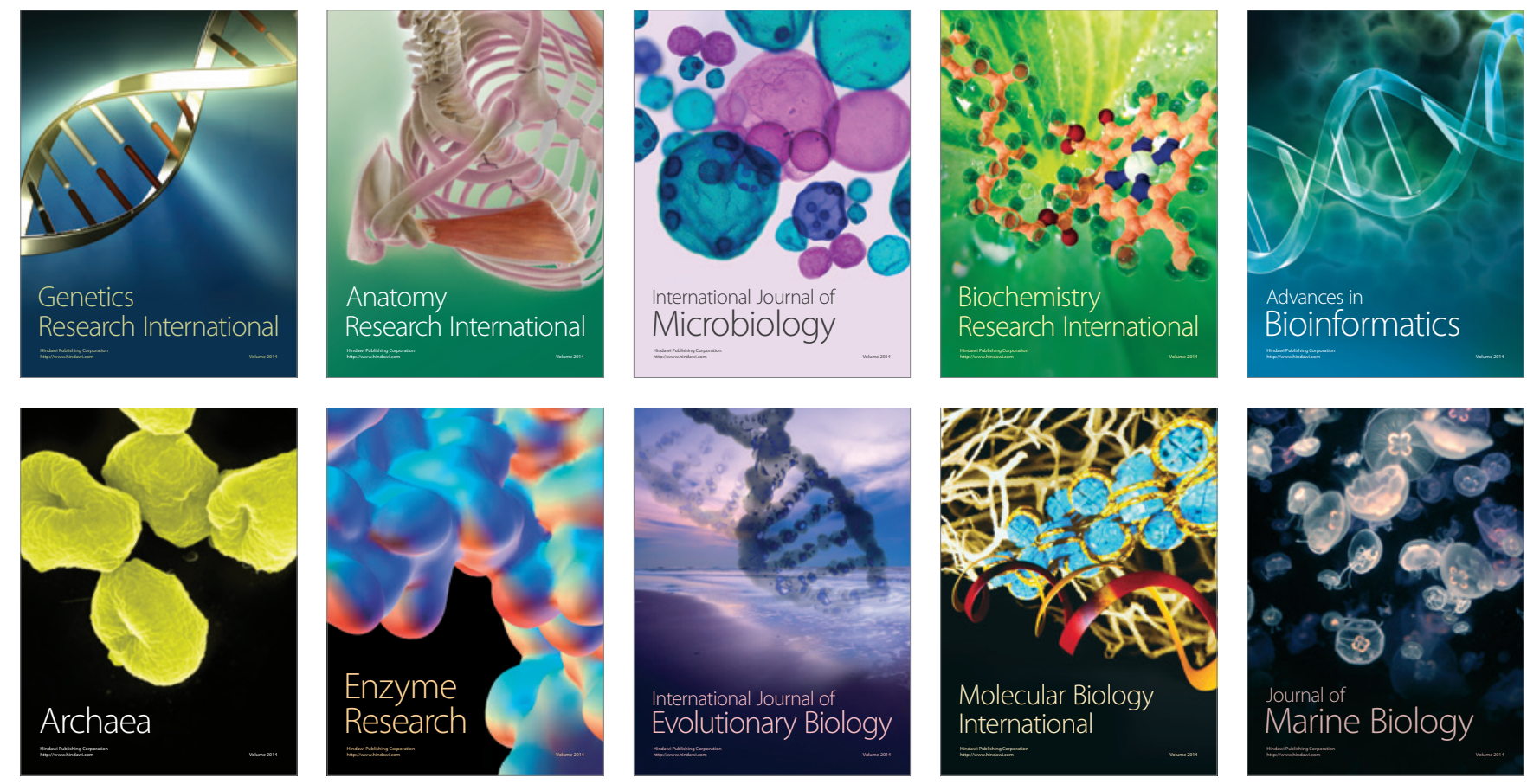